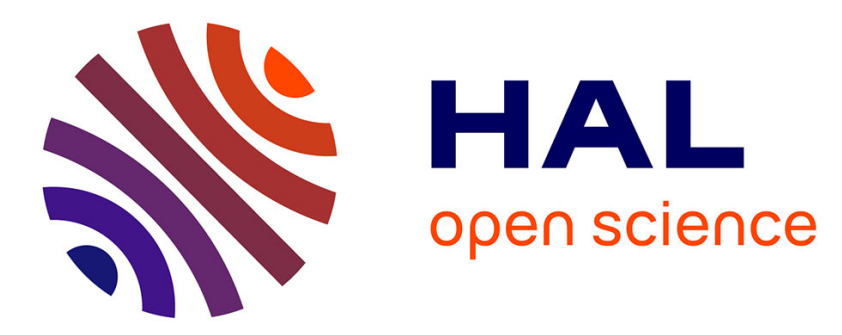

\title{
Nanoscale Aspects of Corrosion on Cultural Heritage Metals \\ Philippe Dillmann
}

\section{To cite this version:}

Philippe Dillmann. Nanoscale Aspects of Corrosion on Cultural Heritage Metals. Philippe Dillmann; Ludovic Bellot-Gurlet; Irène Nenner. Nanoscience and Cultural Heritage, Atlantis Press and the Author, pp.233-252, 2016, Online: 978-94-6239-198-7; Print: 978-94-6239-197-0. 10.2991/978-946239-198-7_8. cea-01338155

\section{HAL Id: cea-01338155 https://hal-cea.archives-ouvertes.fr/cea-01338155}

Submitted on 28 Jun 2016

HAL is a multi-disciplinary open access archive for the deposit and dissemination of scientific research documents, whether they are published or not. The documents may come from teaching and research institutions in France or abroad, or from public or private research centers.
L'archive ouverte pluridisciplinaire HAL, est destinée au dépôt et à la diffusion de documents scientifiques de niveau recherche, publiés ou non, émanant des établissements d'enseignement et de recherche français ou étrangers, des laboratoires publics ou privés. 


\title{
Nanoscale Aspects of Corrosion on Cultural Heritage Metals
}

\author{
Philippe Dillmann
}

\begin{abstract}
Metallic artefacts are an important part of the cultural heritage and must be protected for the future generations. Unfortunately, classical metal protection methods used for example in industry, can in most of cases not be used in the context of the conservation of cultural heritage because artefacts must not be aesthetically modified and any protection treatment must be potentially removable without any damage to the artefact. For that reason, to set up efficient conservation strategies, it is necessary to understand and model the long term corrosion mechanisms. In addition to environmental monitoring and empirical approaches, the fine understanding of the corrosion systems, based on the use of multiscale characterisation techniques and methodologies is a key issue to understand the mechanisms and evaluate the degradation rates. This chapter reviews the cases for which investigations at nano scales are necessary to understand and model in a reliable way the corrosion behaviour of different metals (ferrous alloys and bronzes). Nanoscale investigation, also allows scientists to understand the way intentional patinas were made on ancient bronzes. Lastly, an example of the use of nanotechnology to set up an adapted and innovative protective treatment is given.
\end{abstract}

\section{Introduction}

Metallic cultural heritage cannot be protected by usual industrial anticorrosion methods as painting or inhibiting agents that will cause changes of the external appearence of the artefacts. In this context, the protection of metallic artefacts is a key issue and necessitates sometimes costly and hazardous choices for curators, because they don't know the potential future evolution of their systems, especially with environmental and climatic changes. Besides, at a moment of budget lowering for states and institutions in charge of the cultural heritage protection, it is of primary

\footnotetext{
P. Dillmann $(\bowtie)$

LAPA-IRAMAT, NIMBE, Université de Paris Saclay,

91191 Gif Sur Yvette Cedex, France

e-mail: philippe.dillmann@cea.fr 
interest to take the relevant decisions on conservation or restoration processes. For these reasons and for basic preventive conservation purposes, the degradation processes must be managed in advance on the basis of scientific long-term prediction of risks of damage. This implies a fine knowledge of the corrosion mechanisms involved in the degradation of the metals of the cultural heritage.

During their life and after their abandonment and sometime their burial, metallic artefacts of cultural heritage are submitted to long term corrosion processes, associated with the progressive modification of their surfaces and their covering of corrosion products. The nature of these corrosion products depends on the one hand on the kind of metal that is corroded and, on the other hand, on the kind of environment (soil, atmosphere, marine water...) presenting a specific chemical composition. The understanding of the corrosion processes and their modelling (see Sect. 2.2. in the present book) is a crucial issue for conservation and restoration purposes (Scott and Eggert 2009; Dillmann et al. 2013). In that context, the exact role of the corrosion products in these mechanisms must be understood, because in most of times it controls the corrosion kinetics. Actually the electrochemical reactivity of the involved phases and transport phenomena are critical aspects. From the functional scale of the considered artefacts to the nanoscale, these points must be considered and, actually, several studies demonstrated that, in addition to environmental key parameters and microscale processes, nanoscale phenomenon as the presence of barrier layers or typical reactive products potentially plays a dominant role on the macroscopic behaviour of the artefacts.

Thus, the aim of the first part of this chapter is not to review all the numerous corrosion studies dedicated to cultural heritage that are already published, but to give an overview of the cases where the nanometre scale is crucial to the understanding of the corrosion mechanisms and processes. Another interesting aspect of metals of cultural heritage, especially bronzes, is that some of them were submitted in ancient times, to intentional treatments to form artificial patinas, aiming to modify their aesthetic aspects. Researches are conducted to decipher the nature of the treatments performed by ancient craftsmen and, again, this involves investigations at the nanoscale to decipher the technical gestures. The chapter will present some studies dealing with the analytical strategies and the comprehension of phenomenon in that particular frame. Lastly, a third part, will illustrate the way nanotechnology is involved to set up protection treatments for metallic artefacts of the cultural heritage.

\section{Corrosion Mechanisms}

For most of metals, the stable thermodynamic states in natural conditions are under the form of oxides, sulphurs, chlorides and carbonates. That is the reason why artefacts of cultural heritage are submitted to corrosion processes of various natures in contact with their environment. In most of cases this occurs in presence of water (electrolyte) and other oxidant species, the most frequent one, being oxygen. 
Corrosion is an electrochemical process, implying an electron transfer at different interfaces. Nevertheless, because of the presence of precipitated corrosion products, the corrosion processes cannot be considered as simple interactions between the surface of the metal and an electrolyte. The corrosion product layers are more or less passivating or inhibiting, provoking a lowering of the corrosion rates. The thermodynamic aspects of this protective effect was considered by Pourbaix (1977) who expressed the predominance domains of the constitutive phases of the corrosion products in potential-pH diagrams, depending of the activity (concentration) of the different species in the electrolyte. These potential-pH diagrams are fundamental in corrosion studies because they give an estimation of the nature of the formed corrosion products in function of the environmental conditions but the approach is limited to thermodynamic and static considerations. Moreover this approach considers only a macroscopic scale, and an homogenous composition of the electrolyte in contact with the metal. This is definitively not the case for artefacts corroded during very long periods (centuries), on which thick corrosion layers formed, sometimes of several $100 \mu \mathrm{m}$ or even millimetre in thickness for very corrosive conditions (Dillmann et al. 2013). These thick corrosion layers control the local chemical and electrochemical conditions in the porous network they form and these conditions could drastically change at the micro and nano-scales from the metal corrosion product interface to the outer zone of these corrosion products. That is the reason why, to be understood, these ancient systems must absolutely be investigated at different scales. Moreover, the presence at nanometre scale of specific phases or layer, can control the macroscopic processes. Some examples will be given in the following.

\subsection{Ferrous Alloys}

A non negligible part of artefacts of the cultural heritage made of iron or iron alloys is submitted to atmospheric corrosion. In museum exhibition showcases, it is possible to control the exposure conditions and to keep the artefacts at a low relative humidity. Nevertheless, in most of cases (including outdoor exposure, but also some storage rooms) it is not possible to control these conditions. For example, reinforcing iron elements in Gothic mediaeval cathedrals (see for example Fig. 1), that were put in the monuments during their building (Leroy et al. 2015), are today considered as a integral part of the historic monument and must be protected in the same way than stone. Here, it is obviously not possible to control the environmental conditions and corrosion mechanisms must be understood and monitored to predict the behaviour of the metal and take the right conservation decisions. Corrosion of ferrous alloys under atmospheric conditions during very long periods conducts to the formation of thick layers (about several $100 \mu \mathrm{m})$ made of a mix of oxyhydroxides as goethite $(\alpha-\mathrm{FeOOH})$, lepidocrocite $(\gamma-\mathrm{FeOOH})$, ferroxihyte $(\delta-\mathrm{FeOOH})$ and more or less hydrated oxides as magnetite $\left(\mathrm{Fe}_{3} \mathrm{O}_{4}\right)$, maghemite $\left(\gamma-\mathrm{Fe}_{2} \mathrm{O}_{3}\right)$ or ferrihydrite $\left(5 \mathrm{Fe}_{2} \mathrm{O}_{3} \cdot 9 \mathrm{H}_{2} \mathrm{O}\right)$. In case of the presence of pollutants in the atmosphere, some specific phases as akaganeite 

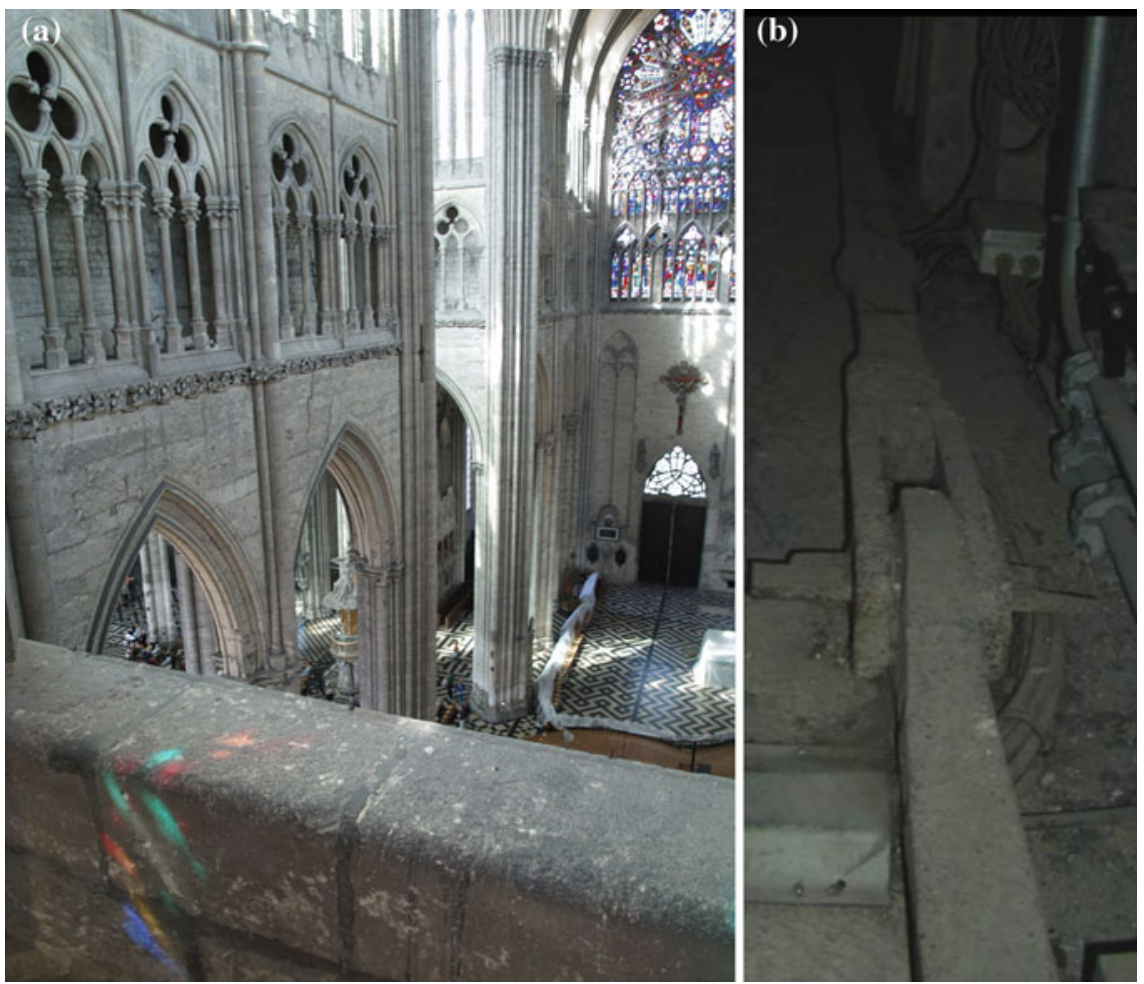

Fig. 1 a View of the triforium of the Amiens Cathedral, $\mathbf{b}$ close view of the reinforcing chain of the triforium

( $\beta-\mathrm{FeOOH})$, a $\mathrm{Cl}$ containing phase, can also constitute the corrosion layer (Dillmann et al. 2004; Monnier et al. 2010a, b; Bouchar et al. 2013). It has been demonstrated that the atmospheric corrosion processes of iron alloys are driven by the so called wet/dry cycle, during which a water electrolyte of several monolayers cyclically deposit and evaporate on the material (Stratmann 1987; Stratmann et al. 1990; Stratmann and Streckel 1990). A very important aspect of this mechanism is that, during the wetting phase, it is not the oxygen of the atmosphere that is the oxidant specie causing the cathodic reaction, but Fe-containing phases, constituting the corrosion layers. It was demonstrated that Fe(III) phases, if they are physically connected to the metallic substrate can be electrochemically reactive and provoke, by their reduction into $\mathrm{Fe}$ (II) species, the oxidation of the $\mathrm{Fe}(0)$ substrate. The electrochemical behaviour of the different phases constituting the corrosion layer was studied by many authors (Antony et al. 2004, 2005, 2007) and a reactivity index was provided to express the potential corrosive effect of the layer (Kashima et al. 2001; Dillmann et al. 2004; Monnier et al. 2010a, 2013). It was also demonstrated that the grain size of the considered phase, highly influence the reactivity and well crystallised nano grains are much less reactive (Monnier et al. 2010b). For that reason, in a general corrosion study on the reinforcing 
iron chain of triforium of the Amiens cathedral, put there in 1498 to avoid the collapse of the cathedral (Dillmann 2011), the grain size of the corrosion products formed was observed and measured (Monnier et al. 2010b). High Resolution TEM and electron energy loss spectroscopy (EELS) in high resolution mode on 130 crystallites of goethite enable to determine that the grain size of this phase varies between 10 and $70 \mathrm{~nm}$ (Fig. 2). This low crystallite size was associated to a relatively low electrochemical reactivity of the rust that could be considered as relatively protective (Monnier et al. 2013). These kinds of approaches are now more and more integrated to corrosion studies dealing with metal of heritage artefacts and are a mean to understand better the evolution of electrochemical reactivity in function of some specific parameters of the constitutive phase of the corrosion layers.

Another important part of the iron based metallic cultural heritage comes from archaeological excavations. Some of these archaeological sites are situated on fields made of specific soils saturated with water. This is for example the case of numerous sites situated in wetland in North of Europe, but also of sites situated under dams, retaining water until their abandon. On some of these sites, in situ conservation
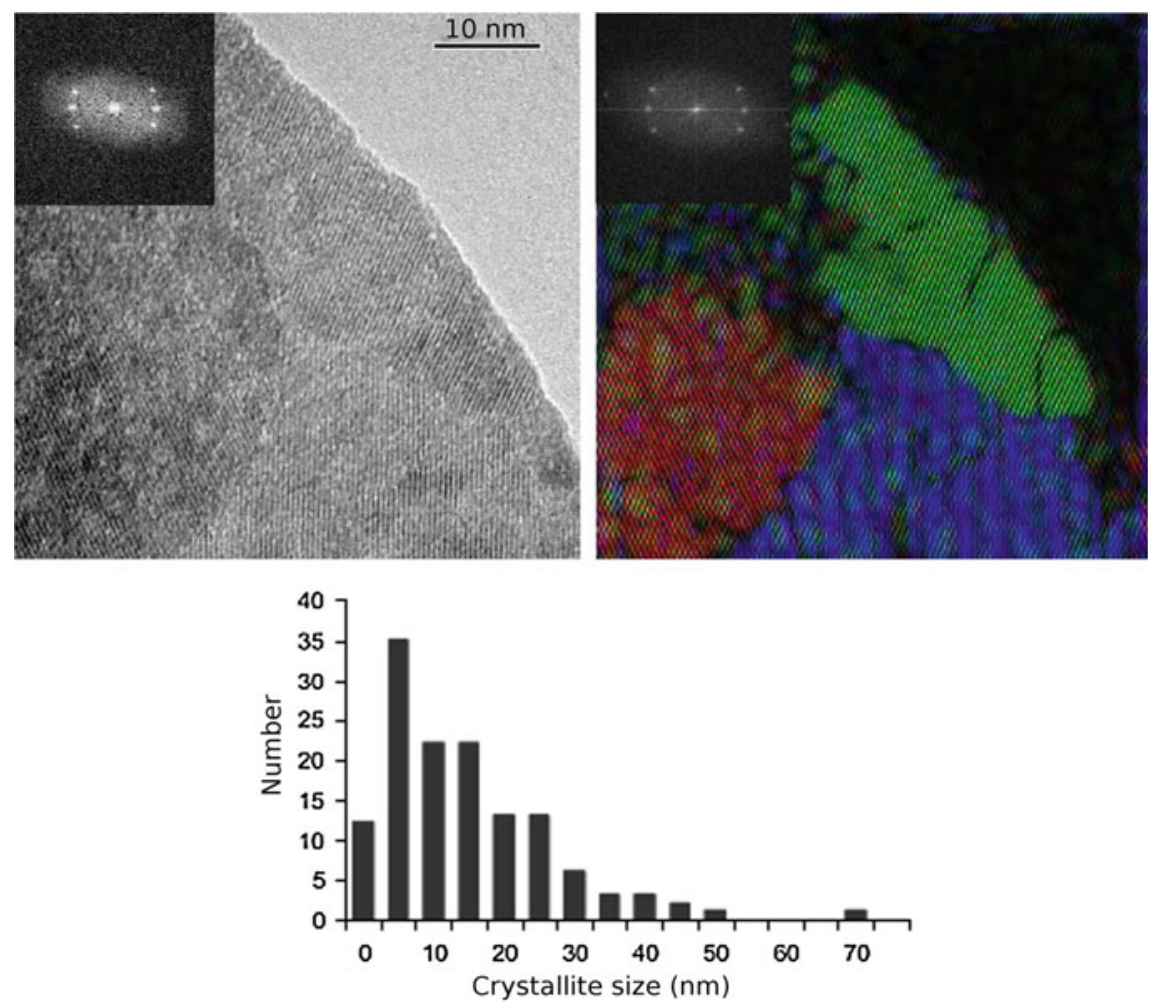

Fig. 2 HR-TEM images of goethite from the corrosion products taken on the reinforcing chain of the triforium of the Amiens cathedral (15th c.), corresponding Fourier transformed image and crystallite sizes (Monnier et al. 2010b) 
is performed. The principle here is to conserve the artefacts buried in the archaeological soil and to monitor and model the environmental conditions and the artefacts behaviour to be sure that these latter are maintained in undisturbed and stable conditions (Corfield 1996; Matthiesen et al. 2004a; Corfield and Williams 2011). As stated by several authors, this can be achieved only by a good and reliable environmental monitoring (Matthiesen et al. 2004a) but also by understanding the degradation mechanisms of the metallic artefacts. Waterlogged soils are characterised by a low oxygen level below a certain depth. This lead corrosionnists to consider in details the very long term corrosion of iron in anoxic conditions. This was recently performed on two archaeological sites on which the corrosion mechanisms were studied. The first one is the site of Nydam Mose in Denmark, dated from the Danish Iron Age and situated in a water meadow. Nydam was a lake in which sacrificial offerings were deposited between 200 and $500 \mathrm{AD}$ (Matthiesen et al. 2004b). All kind of weapons and artefacts made of iron alloys can be found on the site (swords, arrows, spears, etc.). The excavations, that began in the middle of the 19th c. were stopped in 1997 to investigate the feasibility of in situ conservation. The second site is an iron production site dated from the 15th c. AD and situated in Normandy in France. Because of the use of hydraulic power during the middle age to produce iron, a water dam remains on the site (Arribet-Deroin 2001; Dillmann et al. 2003), causing a complete saturation of the soil with water after its abandon and during the burial of the artefacts. On both of these sites, carbonated anoxic conditions were evidenced (Matthiesen et al. 2004a; Saheb et al. 2010a). It has to be stressed here that these conditions of corrosion are interesting to be studied for conservation reasons but also in another completely different frame, the one of the prediction of long term corrosion of steel for the design of over containers for the storage of nuclear wastes (Dillmann et al. 2014). In this latter context, the archaeological artefacts are considered as analogues and bring useful and unique data for modelling and simulating the century-long corrosion processes.

On both of these sites some artefacts (mainly nails) could be analysed using adapted investigations methods of material sciences. It was observed that the corrosion systems were constituted of carbonates as siderite $\left(\mathrm{FeCO}_{3}\right)$ and hydroxicarbonates as chukanovite $\left(\mathrm{Fe}_{2}(\mathrm{OH})_{2} \mathrm{CO}_{3}\right)$ precipitated on the metallic substrate (Saheb et al. 2010b), and forming layers of about $100 \mu \mathrm{m}$. The average corrosion rates deduced from mass balance of the analysed corrosion products and from the initial shape of the artefacts (Matthiesen et al. 2004b; Neff et al. 2005) were very low (i.e. several $\mu \mathrm{m} / \mathrm{year}$ ) and in good agreement with short term corrosion experiments made in laboratory to simulate the corrosion mechanisms (Schlegel et al. 2008, 2014). Besides, electrochemical measurements made by impedance spectroscopy during short term laboratory experiments suggested that the mere presence of the carbonate thick layer was not sufficient to explain the low corrosion rates (because of their relatively high porosity), but that a dense and barrier layer should be present at the interface between the metal and the carbonated corrosion products (Rangel et al. 1986; Castro et al. 1991; Bataillon et al. 2001; Han et al. 2009). To verify this assertion the metal/corrosion product interface of some archaeological artefacts was studied at the nanometric scale by a combination of TEM and Scanning Transmission X ray Microscope (STXM) observations 

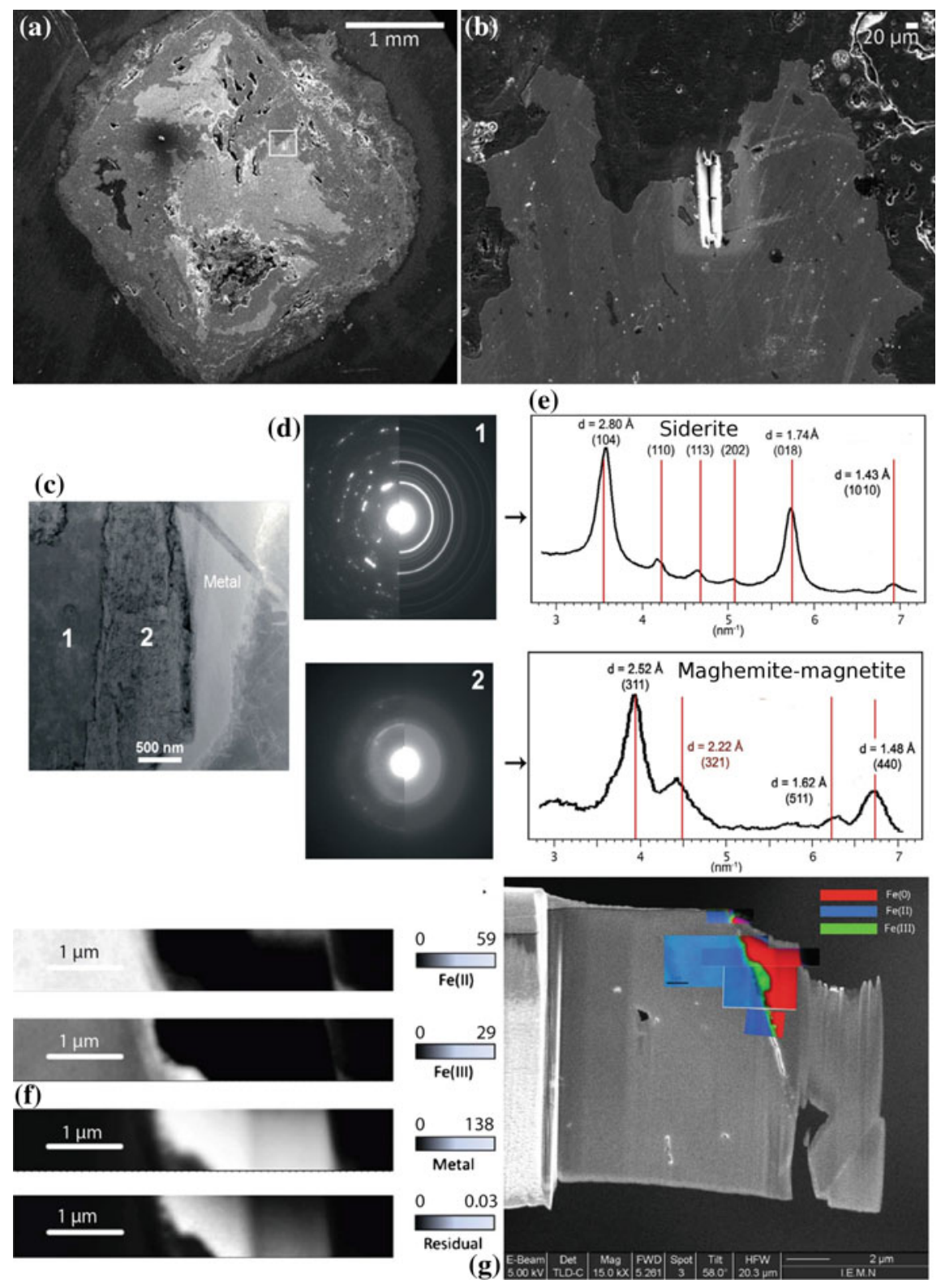

Fig. 3 a SEM image of the cross section of an archaeological iron nail corroded since the 15th c. in an anoxic carbonated environment. b Location of the thin film sample at the metal/corrosion product interface, $\mathbf{c}$ TEM image and associated (d, e) electron diffraction patterns. (f, g) STXM maps obtained at the $\mathrm{Fe} \mathrm{L}$ edge. Repartition of $\mathrm{Fe}(0), \mathrm{Fe}(\mathrm{II})$ and $\mathrm{Fe}(\mathrm{III})$ valences (Michelin et al. 2013; Leon et al. 2014) 
performed on a thin film sample obtained by Focused Ion Beam (FIB) at the metal/corrosion product interface. It was clearly demonstrated that, in addition to the layer of carbonates, an interface nanometric layer varying from 50 to several $100 \mathrm{~nm}$ in thickness was present on the artefacts (Michelin et al. 2013; Leon et al. 2014). This layer is made of a mix of iron oxides (maghemite and magnetite see Fig. 3).

The porosity and protectiveness of the layer were studied by another specific experiment. Another archaeological nail was immersed before any cutting or sampling, in a $\mathrm{D}_{2} \mathrm{O}$ solution reproducing the archaeological pore water of the soil, during 3 month. Then, a transverse section of the nail was examined by nano-SIMS in order to map ${ }^{16} \mathrm{O}$, D and $\mathrm{H}$ distribution (Leon et al. 2014). On Fig. 4, the ${ }^{16} \mathrm{O}$ distribution allows one to distinguish the corrosion products from the metal. The $\mathrm{D} / \mathrm{H}$ map, clearly indicates a D depletion at the metal oxide interface, revealing the hindering role for the transport of water to the metallic interface of the barrier layer made of magnetite and maghemite identified by TEM and STXM at this location. The formation of this nanometric interface layer is explained by some authors by a local acidification at the metal/corrosion product interface due to water hydrolysis during the iron oxidation process (Han et al. 2009). This important observation corroborates the potential protective role of the interfacial layer in the corrosion process, and its influence on the kinetics evoked by some authors (Bataillon et al. 2010). This is now taken into account in further modelling of iron and steel long term corrosion, both for conservation and long term prediction purposes. It is also a good example of a nanometric process controlling a macroscopic corrosion kinetic.
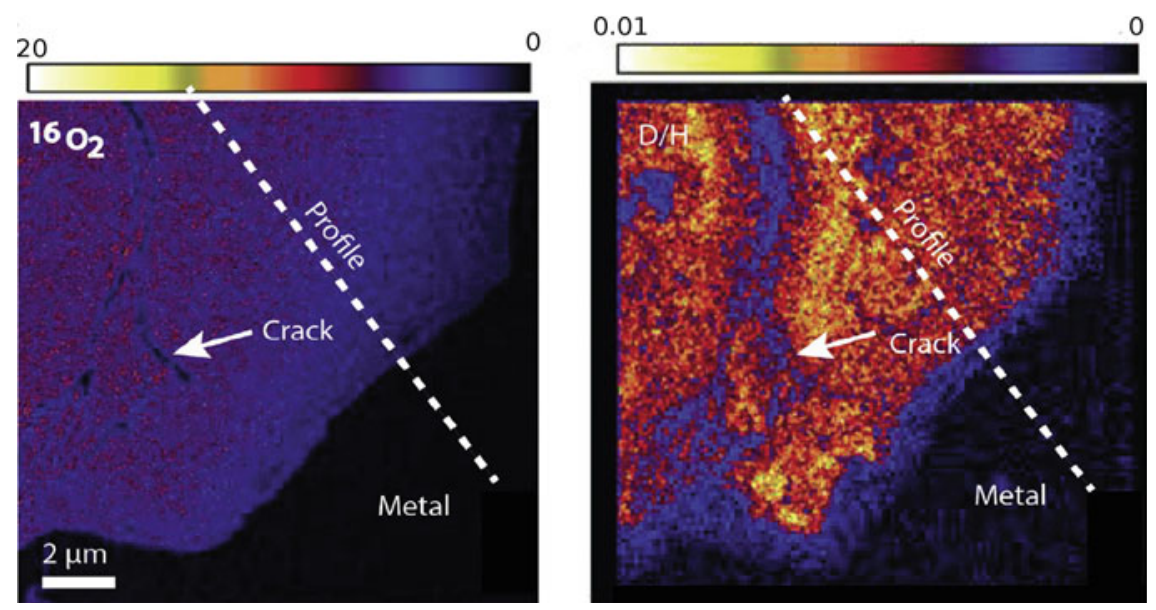

Fig. 4 Nano-SIMS maps of ${ }^{16} \mathrm{O}_{2}$ and $\mathrm{D} / \mathrm{H}$ ratio obtained at the Metal/Corrosion products interface of an archaeological nail from the 15 th c. put 3 month in a $\mathrm{D}_{2} \mathrm{O}$ solution (Leon et al. 2014) 


\subsection{Non-ferrous Alloys}

The outdoor corrosion of ancient "bronzes" (Cu-Sn alloys with sometimes significant quantities of $\mathrm{Zn}$ and $\mathrm{Pb}$ ), conducts to the formation of a protective patina of about $20-50 \mu \mathrm{m}$ of thickness. An important number of studies was dedicated to understand the nature of these patinas that have similarity with the behaviour of pure copper but differs from it because of the presence of alloying elements (Selwyn et al. 1996; Robbiola et al. 1998; Spoto et al. 2000; Ingo et al. 2006; Chiavari et al. 2007). Patina can contain both $\mathrm{Cu}$-rich and $\mathrm{Sn}$ rich compounds, mainly cuprite $\left(\mathrm{Cu}_{2} \mathrm{O}\right)$ or cassiterite $\left(\mathrm{SnO}_{2}\right)$. Moreover, in rainfall conditions, cyclic processes can occur, based on the successive dissolution and leaching phenomenon. In that context it is of primary importance to understand the physico-chemical nature of the patina on the one hand and its electrochemical reactivity on the other hand. This latter information can be obtained by performing cyclic voltammetry or electrochemical impedance spectrometry (EIS) using a cavity electrode, allowing to test small quantities of scrapped powders (Chiavari et al. 2007; Bernard and Joiret 2009). Concerning physico-chemical investigations at low scales, several studies demonstrate the important role of nanocrystalline areas with a specific behaviour in the patina. For example, Chiavari et al. (2007) by High Resolution Transmission Electronic Microscopy investigations coupled with EDS on powder scrapped on a French outdoor Bronze monument (Monument to Francis Garnier 1898, Fig. 5), confirms the presence of nanocrystals in the pale green external patina that is depleted in copper and enriched in tin, probably constituted of oxide or hydroxide compounds (Fig. 6). This kind of nanoparticles was also evidenced in the corrosion

Fig. 5 Monument to Charles Garnier, Paris (Chiavari et al. 2007)

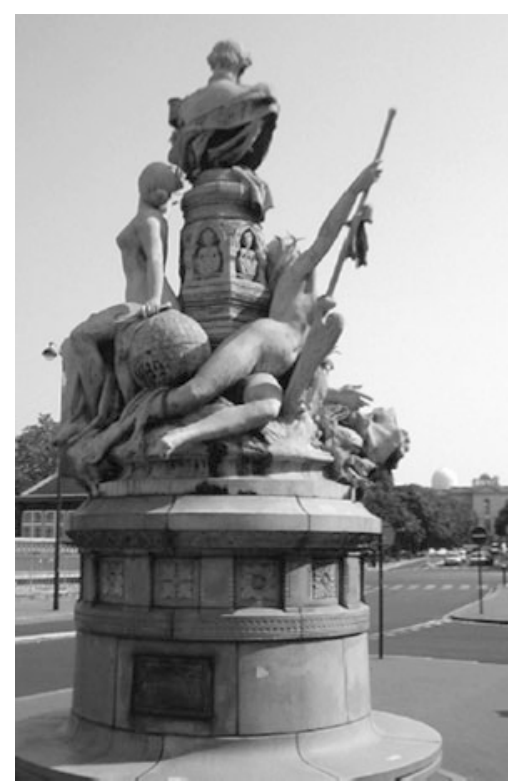



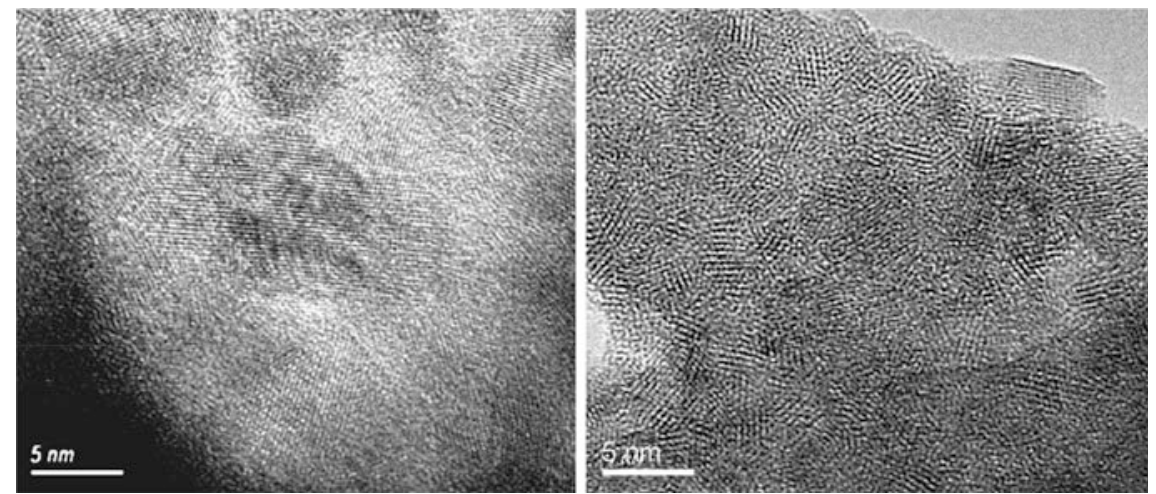

Fig. 6 HR-TEM lattice images of pale green patina from an outdoor bronze monument. Presence of $5 \mathrm{~nm}$ nanocrystals (Chiavari et al. 2007)

products of ancient Chinese mirrors. Several studies were interested into the fine characterisation of the $\mathrm{SnO}_{2}$ nanometric particles that formed during the corrosion process of black mirrors, made of a $\mathrm{Cu}$-Sn alloy because, they potentially influence the corrosion resistance of the artefact. Wang et al. (1995), combining TEM (using Selected Area Electron Diffraction) and XAS, manage to index the structure of cassiterite $\left(\mathrm{SnO}_{2}\right)$, attributed to an hypothetical compounds of $\mathrm{Sn}_{1-\mathrm{x}}(\mathrm{CuFePbSi})_{\mathrm{x}} \mathrm{O}_{2}$.

Ancient mirrors were made of tin amalgam (Hadsund 1993). These kinds of mirrors were used from the 16th $\mathrm{c}$. to the beginning of the 20th c. To obtain these mirrors, first, a $100 \mu \mathrm{m}$ film of Sn is laid on a flat plate of marble. Then, mercury is poured onto the tin film. Finally a polished glass is put on the amalgam. The process is detailed in (Herrera et al. 2009). The obtained amalgam after $24 \mathrm{~h}$ is made of a two phase system: tin mercury compounds surrounded by a mercury rich liquid phase (Herrera et al. 2008a). The corrosion of this amalgam causes the final formation of $\mathrm{SnO}_{2}$ after an initial precipitation of thermodynamically unstable $\mathrm{SnO}$ particles (Duran et al. 2008; Herrera et al. 2008b). Because mercury is volatile, after the ageing processes the final altered layer is made of divided $\mathrm{SnO}_{2}$ particles. Herrera et al. (2009) studied in details the nature of these particles on an Andalusian baroque mirror, comparing an altered and an non-altered zone, by performing SEM, XRD and TEM. The very large peaks obtained by XRD on the surface of the altered zones of the mirrors indicate the presence of small size particles (estimated size by Sherrer law: 4-5 nm). TEM images were acquired on the $\mathrm{SnO}_{2}$ particles and Selected Area Electron Diffraction (SEAD) was performed confirming the presence of $5 \mathrm{~nm}$ particles and aggregates (Fig. 7). Authors proposed that this layer of nanocrystalline corrosion products protects the metal very efficiently because nanometric crystals seems to have a lower surface activity and, consequently forms a more protective layer.

The nature of the tin containing phases developed after corrosion processes of bronzes is also an issue for archaeological artefacts corroded in soil. Robbiola et al. (1998) proposed a mechanism based on selective dissolution on copper. Two types 

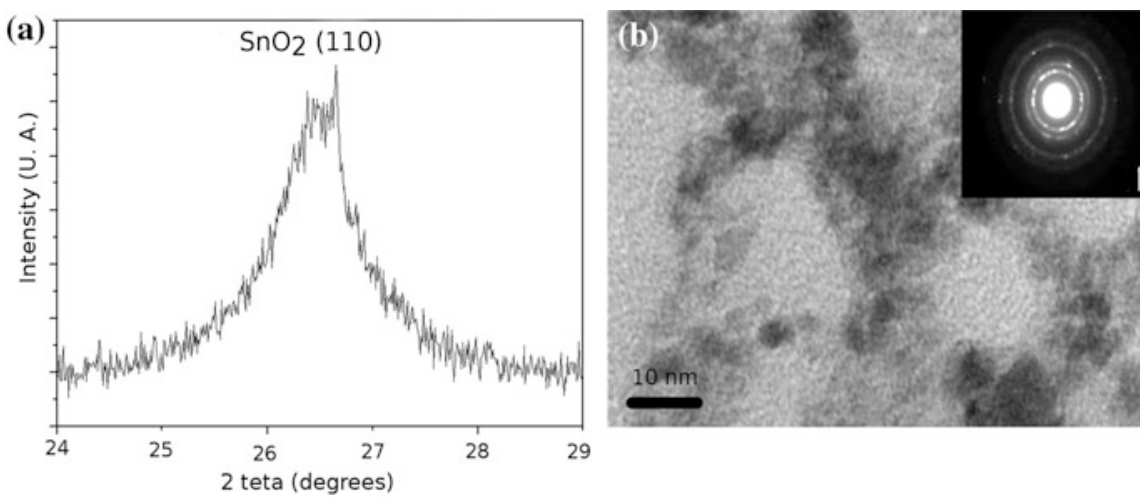

Fig. 7 a XRD at incidence angle $\gamma=5^{\circ}$ of $\mathrm{SnO}_{2}$ powder separated from the surface of a corroded Andalusian baroque mirror by the sonication method b TEM image and electron diffraction patterns from $\mathrm{SnO}_{2}$ particles from the surface of a corroded mirror (Herrera et al. 2009)

of corrosion profiles are evidenced on archaeological artefacts depending on the nature and aggressiveness of the environment. In the type I, formed in a low aggressive environment, a protective barrier enriched in tin forms on the metal. In the case of more aggressive environment, for example containing chloride, accumulating at the metal/corrosion layer interface, localised corrosion phenomena are observed (type II patterns). In these processes, the nature of the tin layer and the way it protects the metal was a long time in discussion. To enlighten that point, Muller et al. (Muller et al. 2010, 2013) performed a study on coupons simulating the type I pattern after corrosion in sulphate aqueous solution. Different kind of bronzes were tested $\left(\alpha-\mathrm{Cu}(\mathrm{Sn})\right.$ and $\left.\mathrm{CuSn}_{7}\right)$. The tin enriched phases where tested after anodic polarisation simulating the aging by electrochemical methods, X-ray spectroscopy (XPS), Auger Electron Spectroscopy (AES) and TEM. STEM and XPS investigations reveal that the formed passivating layer is of about $15 \mathrm{~nm}$ thick.
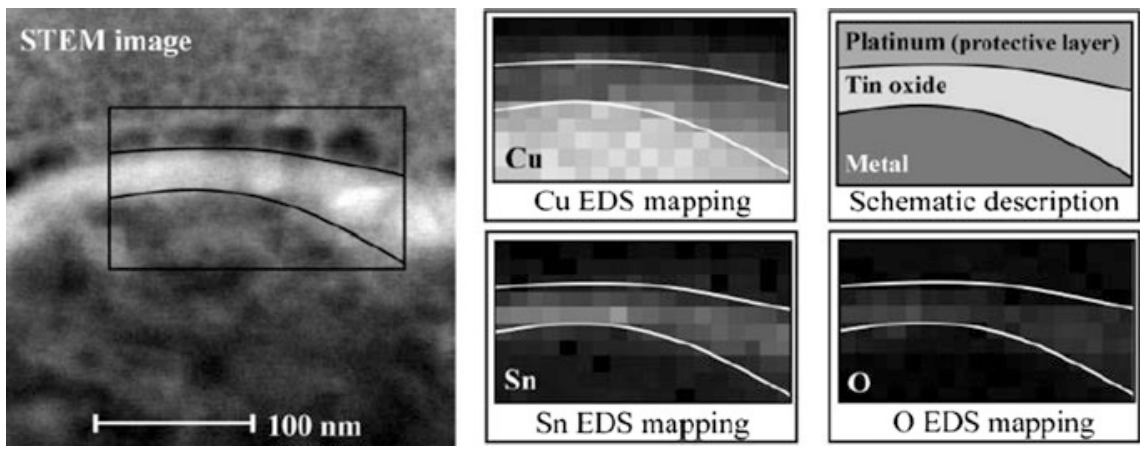

Fig. 8 STEM image and EDS maps of the passive Sn containing passivating layer on a bronze coupon simulating corrosion in a low aggressive environment (soil) (Muller et al. 2010) 
It is made of a mix at this scale of $\mathrm{SnO}_{2}$ (cassiterite) and $\mathrm{Cu}_{2} \mathrm{O}$ (cuprite), despite an external layer of pure cuprite can not be excluded (Fig. 8).

\section{Artificial Patinas and Ancient Surface Treatments on Bronzes}

As for ceramic or glasses (see other chapters of this book), the knowledge of the technical development of ancient societies needs to understand the technical gestures applied by ancient craftsmen to form and decorate metals. In several cases processes took place at nanometre scale. To modify the external aspect of bronzes, and especially their colour, different kind of artificial treatments (chemical or physic-chemical) were applied on the alloys, in order to form a specific patina with different colours (reddish and dark brown, or black). The exact chemical structure and formation mechanisms of these artificial patina were in debate until the recent use, combined to classical characterisation techniques, of fine surface analysis techniques allowing one to investigate the patinas at lower scales.

For example, in different regions of the world and at different periods (Egypt 2nd millenary BC, Roman Empire 1st c. AD, China 4th c. AD or Japan 14th c. AD), a typical chemical treatment was applied on bronzes or coppers to obtain what is called "Black bronzes" or "Black coppers". These treatments, giving a black or velvet colour to the surface of the artefact, were applied on specific copper alloys containing gold (1-8 wt $\%$ ) and silver (1-4 wt $\%)$. Combined to micro-scale investigations (micro-Raman spectroscopy, SEM, ICP-AES...) in a tailored step by step analytical strategy, a comprehensive study performed these last years on several pieces from the Louvre Museum (Aucouturier et al. 2010), used an Ion Beam Analysis approach by Rutherford Back Scattering (RBS) to decipher the nature of the layer with a resolution of about $100 \mathrm{~nm}$. It was demonstrated that small amounts of $\mathrm{Au}$ and $\mathrm{Ag}$ inside $\mathrm{Cu}_{2} \mathrm{O}$ layer allowed to change the colour and to obtain the desired one.

Artificial patinas on bronzes could be obtained by hot (heat colouring, torch techniques) or cold treatments. Hot treatments were performed by successive cycles consisting of a first oxidation of the metal generating a thin layer of oxides, followed by the application of a solution on the oxidized area. These successive cycles allowed the craftsman to build progressively the desired colour. The obtained colour is the result of a complex combination of cycles, temperature and composition of the applied chemical solution (Hiorns 1911; Hughes and Rowe 1982). The fact that this treatment is performed by cycles, generates a thin patina with compositional and structural heterogeneities lower than the $\mu \mathrm{m}$ in thickness. Thus, to understand their formation processes, chemical and structural profiles must be performed with a nanoscale resolution. For that reason, Balta et al. (2009), to better understand the reddish brown, dark brown and black patinas obtained on bronzes and coppers by torch techniques based on ferric chloride, ferric nitrate and 

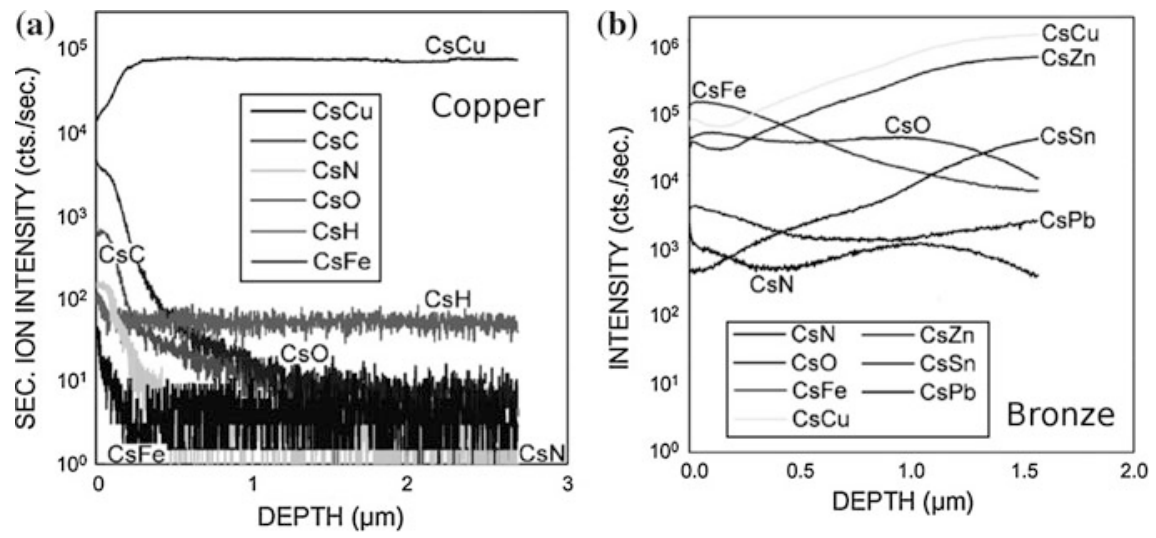

Fig. 9 a Normalised D-SIMS depth profile on a copper sample after presenting a $200 \mathrm{~nm}$ reddish brown nitrate solution patina, b Normalised D-SIMS depth profile on a bronze sample after presenting a $1600 \mathrm{~nm}$ reddish brown nitrate solution patina (Balta et al. 2009)

potassium sulphide solutions, performed Secondary Ion Mass Spectrometry (SIMS) and XPS on artificially treated coupons presenting the most common composition of 19th c. bronzes. XPS allowed to study the oxidation states of the different components and D-SIMS revealed the depth of penetration of different exogenous elements coming from the solution $(\mathrm{O}, \mathrm{C}, \mathrm{H}, \mathrm{Cl}, \mathrm{Fe}, \mathrm{K})$. The results (Fig. 9) demonstrate the heterogeneous distribution of exogenous elements in the thickness of the patina, leading to different colouring effects. A selective dissolution of the different elements of the bronze alloy $(\mathrm{Cu}, \mathrm{Zn}, \mathrm{Sn}$ and $\mathrm{Pb})$ is also evidenced. It was also observed that the colour and the texture of patinas are influenced by nature and concentration of the solutions applied. Last but not least, the successive cycles of application of the patination solutions were tracked and found in the elemental depth profile.

\section{Nano Coatings Against Corrosion}

The protection of metallic artefacts of the cultural heritage against further corrosion degradation is a key issue. A way to reach that goal is to store the artefacts in controlled environment with low RH, free of pollutants and of aggressive gases. Nevertheless, this is not always possible, due to economical or practical considerations. For that reason, another solution would be to apply a protective coating on the artefacts to separate it from the environment. Nevertheless, for cultural heritage metal, the treatment must not alter the aesthetic aspect of the object and must be removable. Most of the treatments that are applied today as waxes (Degrigny 2010; Shashoua and Matthiesen 2010) or carboxylate (Hollner et al. 2010), deal with layers with thickness of several micron or tenth of microns, susceptible to modify 
the external aspect after applying. Moreover, the durability of the efficiency of these treatment is questioned. Concerning the specific case of silver, submitted to a tarnishing effect in several environment, some successful attempts were made by using nanotechnology to develop a nanometre scale protective layer (Marquardt et al. 2015). For this metal, nitrocellulose treatments, manually applied are usually used. They are unfortunately non uniform, and their efficiency on long time period is limited. Particularly this compounds is well know to degrade and yellow under UV exposure, causing an undesirable colour on the artefact with time (Baše et al. 2010). At the contrary, to our knowledge, Atomic Layer Deposited (ALD) thin film of metal oxide does not present this limitation. As explained by Marquandt et al., ALD is a thermally activated gas phase process for synthesizing thin solid films by sequentially exposing an object to a series of two or more gaseous reactants, each of which undergoes self-limiting chemisorption surface reactions (Leskelä and Ritala 2002; Puurunen 2005). The artefacts to be covered is placed in the vacuum chamber where the process take place, in which a metal organic precursor and an oxiding co-reactant are pulsed. For example, in order to depose an alumina $\left(\mathrm{Al}_{2} \mathrm{O}_{3}\right)$ coating, the metal-organic compound is trimethylaluminium (TMA) and the co-reactant, water. The precursor only reacts with the hydroxyl groups already present on the surface of the metal. Once all hydroxyl sites have reacted, additional exposure to the precursor will not results in an additional grow and thus, only a monolayer of coating is formed on the metallic surface. The co reactant is then introduced in a second stage to form the final $\mathrm{Al}_{2} \mathrm{O}_{3}$ monolayer. The obtained surface of the $\mathrm{Al}_{2} \mathrm{O}_{3}$ is also hydroxyl terminated, so the process can be repeated to obtain the final desired $\mathrm{Al}_{2} \mathrm{O}_{3}$ coated layer (Fig. 10). The self limiting nature of the process is the guaranty of the formation of a dense conformal and compact protecting film forming a very effective diffusion barrier against corrosion (Matero et al. 1999; Abdulagatov et al. 2011; Díaz et al. 2011a, b; Carcia et al. 2011). For cultural heritage applications, the thickness of the coating layer must be sufficiently thick to be an effective diffusion barrier for corrosion processes and sufficiently thin to be

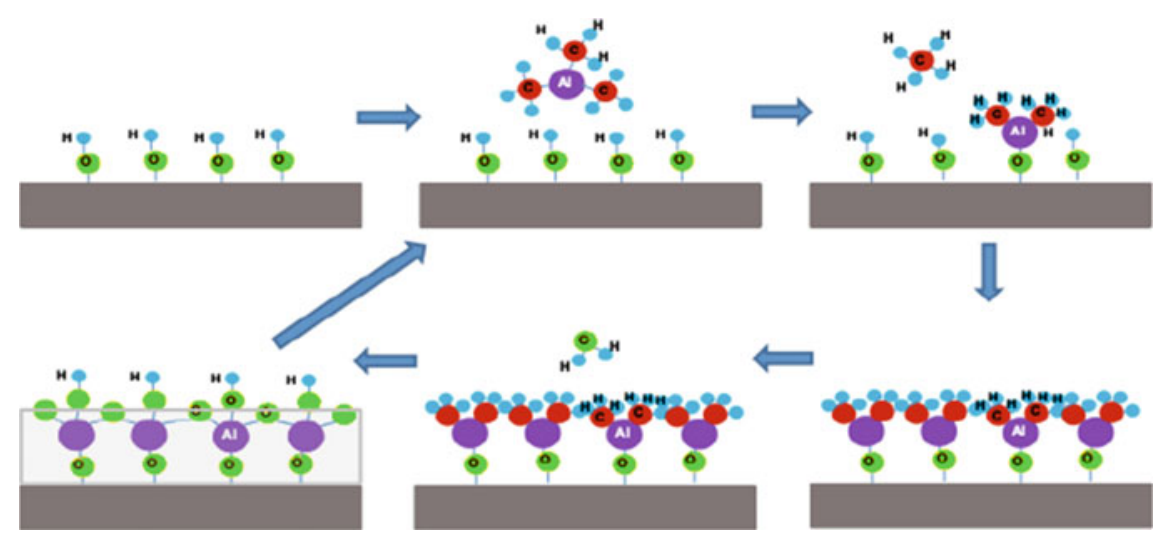

Fig. 10 Different stages of $\mathrm{ALD}$ for an $\mathrm{Al}_{2} \mathrm{O}_{3}$ coating (Marquardt et al. 2015) 
optically transparent. Recent studies demonstrate that this optimal layer is about 20-100 nm (Paussa et al. 2011; Marquardt et al. 2015). As ALD is a non directional technique (contrary to spray based technique for example), all surfaces of even a complex artefact can be coated uniformly. Recently, specific systems working at low temperature (and consequently not disturbing the structure of the metallic surface) and atmospheric pressure have been developed and are especially adapted to the case of heritage artefacts.

Another promising method for protecting cultural heritage metals against corrosion is the deposit of a nano layer of silicon containing organic compounds (organosilicons) by Plasma Enhanced Chemical Vapor deposition (PECVD) (Angelini et al. 2004; d'Agostino et al. 2005). This method is highly versatile and allows one to test different deposition conditions and, thus, thin films characteristics (D’Agostino et al. 1997; Fracassi et al. 2003).

The protectiveness of the treatment was tested on different kind of metallic substrates as silver and copper alloys (Angelini et al. 2004, 2006). The $\mathrm{SiO}_{2}$-like coatings are characterized by high chemical and thermal stability, good dielectric properties, low gas permeability, etc. The surface quality of a thin film deposited under different conditions on reference copper alloys presenting different roughness was evaluated by AFM observations (Fig. 11) by Angelini et al. (2006).

The high degree of adaptability to different kind of surfaces is a key factor for the protection of cultural heritage artefacts, which sometimes present complex shapes. Another very interesting feature of plasma polymerisation processes is that they can be preceded in the same chamber by a first cleaning stage or passivating treatment. During this etching stage the surface ion bombardment can be carefully controlled in order to avoid any damage at nanoscale.
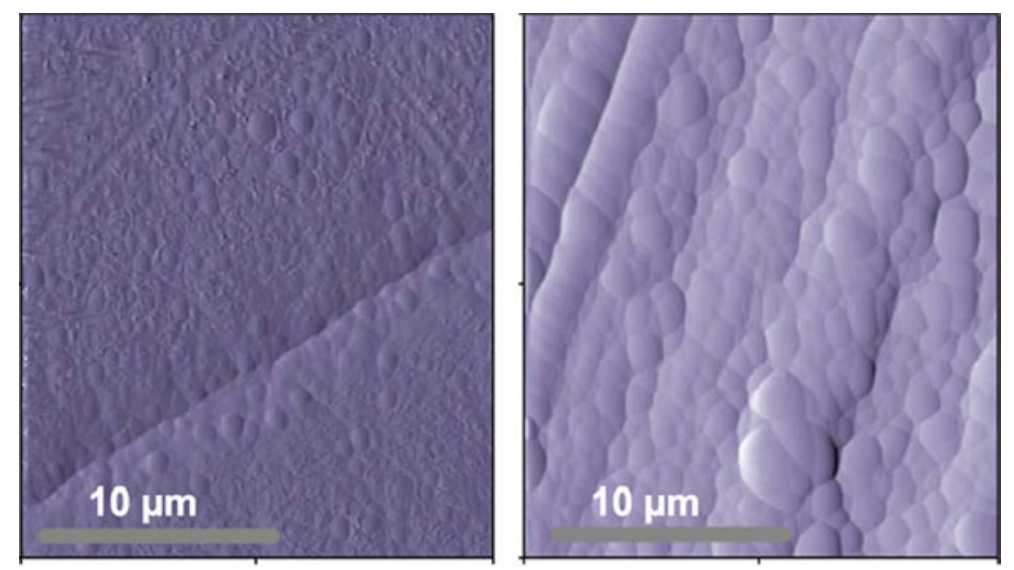

Fig. 11 AFM images of $\mathrm{SIO}_{2}$-like films deposited by PECVD on copper based reference alloys of different roughness, representative of metals of cultural heritage (Angelini et al. 2006) 


\section{Conclusion}

This short review aimed to show how it is crucial, in order to completely understand a corrosion mechanism and its dynamic over centuries in a given environment, to study the system at different scales, including the nanometre one. It has been shown that, on iron based metals, even if corrosion layers of several hundred micrometers are observed, in some cases, mechanisms at the nanometer scale control the kinetics or the electrochemical reactivity of the considered systems. The same for ancient bronzes on which the formation of tin containing phases and their protective ability can not be understood without an investigation at the nanoscale. Concerning patinas naturally or artificially formed on ancient bronzes, the use of surface investigation techniques, allowing one to model the valence and the chemistry of corrosion layers with a thickness lower than $1 \mu \mathrm{m}$ and in which nanometric composition variation can be linked to ancient technical gestures, is a key approach. Last but not least, the use of nanotechnology to set up protection treatment adapted to the particular case of conservation of heritage artefacts will be to our opinion an important option for future approaches, for metallic artefacts as for other materials (see Sects. 3.2 and 3.3 in the present book) as demonstrated here for silver. Thus, it is no doubt that nano-characterisation techniques, nanotechnologies and nanosciences, will be more and more integrated in the various approaches linked to corrosion and protection of metals of the cultural heritage.

\section{References}

Abdulagatov AI, Yan Y, Cooper JR, Zhang Y, Gibbs ZM, Cavanagh AS, Yang RG, Lee YC, George SM (2011) $\mathrm{Al}_{2} \mathrm{O}_{3}$ and $\mathrm{TiO}_{2}$ atomic layer deposition on copper for water corrosion resistance. ACS Appl Mater Interfaces 3:4593-4601. doi:10.1021/am2009579

Angelini E, Fracassi F, D’Agostino R, Grassini S, Rosalbino F (2004) PECVD of organosilicon thin films for corrosion protection of metals. In: Trends in electrochemistry and corrosion at the beginning of the 21 st century, p 20

Angelini E, Grassini S, Solorzano G, Campos GD, De Caro T (2006) Integrated approach to the characterization and conservation of artefacts of the Brazilian colonial period. Appl Phys A-Mater Sci Process 83:485-491. doi:10.1007/s00339-006-3544-x

Antony H, Peulon S, Legrand L, Chaussé A (2004) Electrochemical synthesis of lepidocrocite thin films on gold substrate-EQCM, IRRAS, SEM and XRD study. Electrochim Acta 50:10151021

Antony H, Legrand L, Maréchal L, Perrin S, Dillmann P, Chaussé A (2005) Study of lepidocrocite electrochemical reduction in neutral and slightly alkaline solutions at $25{ }^{\circ} \mathrm{C}$. Electrochim Acta 51:745-753

Antony H, Perrin S, Dillmann P, Legrand L, Chaussé A (2007) Electrochemical study of indoor atmospheric corrosion layers formed on ancient iron artefacts. Electrochim Acta 52:7754-7759

Arribet-Deroin D (2001) Fondre le fer en gueuses au XVIe siècle. Le haut fourneau de Glinet en pays de Bray (Normandie). Paris I Sorbonne, Paris

Aucouturier M, Mathis F, Robcis D, Castaing J, Salomon J, Pichon L, Delange E, Descamps S (2010) Intentional patina of metal archaeological artefacts: non-destructive investigation of 
Egyptian and Roman museum treasures. Corros Eng Sci Technol 45:314-321. doi:10.1179/ $147842210 x 12710800383567$

Balta IZ, Pederzoli S, Iacob E, Bersani M (2009) Dynamic secondary ion mass spectrometry and X-ray photoelectron spectroscopy on artistic bronze and copper artificial patinas. Appl Surf Sci 255:6378-6385. doi:10.1016/j.apsusc.2009.02.020

Baše T, Bastl Z, Havránek V, Lang K, Bould J, Londesborough MGS, Macháček J, Plešek J (2010) Carborane-thiol-silver interactions. A comparative study of the molecular protection of silver surfaces. Surf Coat Technol 204:2639-2646. doi:10.1016/j.surfcoat.2010.02.019

Bataillon C, Musy C, Roy M (2001) Corrosion des surconteneurs de déchets, cas d'un surconteneur en acier faiblement allié. J Phys IV France 267-274

Bataillon C, Bouchon F, Chainais-Hillairet C, Desgranges C, Hoarau E, Martin F, Perrin S, Tupin M, Talandier J (2010) Corrosion modelling of iron based alloy in nuclear waste repository. Electrochim Acta 55:4451-4467

Bernard MC, Joiret S (2009) Understanding corrosion of ancient metals for the conservation of cultural heritage. Electrochim Acta 54:5199-5205. doi:10.1016/j.electacta.2009.01.036

Bouchar M, Foy E, Neff D, Dillmann P (2013) The complex corrosion system of a medieval iron rebar from the Bourges' Cathedral. Characterization and reactivity studies. Corros Sci 76:361372. doi:10.1016/j.corsci.2013.07.007

Carcia PF, Mclean RS, Sauer BB, Reilly MH (2011) Atomic layer deposition ultra-barriers for electronic applications, strategies and implementation. J Nanosci Nanotechnol 11:7994-7998. doi:10.1166/jnn.2011.5075

Castro EB, Vilche JR, Arvia AJ (1991) Iron dissolution and passivation in $\mathrm{K}_{2} \mathrm{CO}_{3}-\mathrm{KHCO}_{3}$ solutions. rotating ring disc electrode and XPS studies. Corros Sci 32:37-50. doi:10.1016/ 0010-938X(91)90062-T

Chiavari C, Rahmouni K, Takenouti H, Joiret S, Vermaut P, Robbiola L (2007) Composition and electrochemical properties of natural patinas of outdoor bronze monuments. Electrochim Acta 52:7760-7769

Corfield M (1996) Preventive conservation for archaeological sites. In: Archaeological conservation and its consequences preprints of the contributions to the copenhagen congress, 26-30 August 1996. London, pp 32-37

Corfield M, Williams J (2011) Review of "Preservation of archaeological remains in situ (PARIS 4)." e-conservation magazine 24-29

D'Agostino R, Fracassi F, Favia P (1997) Plasma processing of polymers. Kluwer Academic Publishers, Berlin

d'Agostino R, Fracassi F, Palumbo F, Angelini E, Grassini S, Rosalbino F (2005) Protection of silver-based alloys from tarnishing by means of plasma-enhanced chemical vapor deposition. Plasma Proc Polym 2:91-96. doi:10.1002/ppap.200400031

Degrigny C (2010) Use of artificial metal coupons to test new protection systems on cultural heritage objects: manufacturing and validation. Corros Eng Sci Technol 45:367-374. doi:10. 1179/147842210X12754747500649

Díaz B, Härkönen E, Światowska J, Maurice V, Seyeux A, Marcus P, Ritala M (2011a) Low-temperature atomic layer deposition of $\mathrm{Al}_{2} \mathrm{O}_{3}$ thin coatings for corrosion protection of steel: surface and electrochemical analysis. Corros Sci 53:2168-2175. doi:10.1016/j.corsci. 2011.02.036

Díaz B, Światowska J, Maurice V, Seyeux A, Normand B, Härkönen E, Ritala M, Marcus P (2011b) Electrochemical and time-of-flight secondary ion mass spectrometry analysis of ultra-thin metal oxide $\left(\mathrm{Al}_{2} \mathrm{O}_{3}\right.$ and $\left.\mathrm{Ta}_{2} \mathrm{O}_{5}\right)$ coatings deposited by atomic layer deposition on stainless steel. Electrochim Acta 56:10516-10523. doi:10.1016/j.electacta.2011.02.074

Dillmann P (2011) From Soissons to Beauvais : the use of iron in some French cathedrals. In: Hosek J, Cleere H, Lubomir Mihok (eds) The archaeometallurgy of iron-recent developments in archaeological and scientific research. Prague, pp 173-196

Dillmann P, Arribet-Deroin D, Vega E, Benoit P (2003) Early modern cast iron and iron at Glinet. In: Jensen I-MP, Ohman U (eds). Jernkontorets Bergshistorika Utskott, pp 99-106 
Dillmann P, Mazaudier F, Hoerle S (2004) Advances in understanding atmospheric corrosion of iron I-rust characterisation of ancient ferrous artefacts exposed to indoor atmospheric corrosion. Corros Sci 46:1401-1429

Dillmann P, Watkinson D, Angelini E, Adriens A (2013) Corrosion and conservation of cultural heritage metallic artefacts. Woodhead publishing, Oxford

Dillmann P, Neff D, Féron D (2014) Archaeological analogues and corrosion prediction: from past to future. A review. Corros Eng Sci Technol 49:567-576. doi:10.1179/1743278214Y. 000000214

Duran A, Herrera LK, de Haro MCJ, Justo A, Perez-Rodriguez JL (2008) Non-destructive analysis of cultural heritage artefacts from Andalusia, Spain, by X-ray diffraction with Göbel mirrors. Talanta 76:183-188. doi:10.1016/j.talanta.2008.02.025

Fracassi F, d'Agostino R, Palumbo F, Angelini E, Grassini S, Rosalbino F (2003) Application of plasma deposited organosilicon thin films for the corrosion protection of metals. Surf Coat Technol 174-175:107-111. doi:http://dx.doi.org/10.1016/S0257-8972(03)00422-5

Hadsund P (1993) The tin-mercury mirror: its manufacturing technique and deterioration processes. Stud Conserv 38:3-16. doi:10.1179/sic.1993.38.1.3

Han J, Young D, Colijn H, Tripathi A, Nešić S (2009) Chemistry and structure of the passive film on mild steel in $\mathrm{CO}_{2}$ corrosion environments. Ind Eng Chem Res 48:6296-6302. doi:10.1021/ ie $801819 y$

Herrera LK, Duran A, Franquelo M, Gonzales-Elipe A, Espinos J, Rubio-Zuazo J, Castro G, Justo A, Perez-Rodriguez JL (2008a) Study by grazing incident diffraction and surface spectroscopy of amalgams from ancient mirrors. Open Chemistry 7:47-53

Herrera LK, Duran A, Franquelo ML, de Haro MCJ, Erbez AJ, Perez-Rodriguez JL (2008b) Studies of deterioration of the tin-mercury alloy within ancient Spanish mirrors. J Cult Heritage 9(Supplement):e41-e46. doi:10.1016/j.culher.2008.06.007

Herrera LK, Justo A, Perez-Rodriguez JL (2009) Study of nanocrystalline $\mathrm{SnO}_{2}$ particles formed during the corrosion processes of ancient amalgam mirrors. J Nano Res 8:99-107

Hiorns AH (1911) Metal-colouring and bronzing. MacMillan \& Co, London

Hollner S, Mirambet F, Rocca E, Reguer S (2010) Evaluation of new non-toxic corrosion inhibitors for conservation of iron artefacts. Corros Eng Sci Technol 45:362-366. doi:10.1179/ $147842210 x 12732285051311$

Hughes R, Rowe M (1982) The colouring, bronzing and patination of metals. Crafts Council, London

Ingo GM, De Caro T, Riccucci C, Angelini E, Grassini S, Balbi S, Bernardini P, Salvi D, Bousselmi L, Cilingiroglu A, Gener M, Gouda VK, Al Jarrah O, Khosroff S, Mahdjoub Z, Al Saad Z, El-Saddik W, Vassiliou P (2006) Large scale investigation of chemical composition, structure and corrosion mechanism of bronze archeological artefacts from Mediterranean basin. Appl Phys A-Mater Sci Process 83:513-520. doi:10.1007/s00339-006-3550-z

Kashima K, Hara S, Kishikawa H, Miyuki H (2001) Evaluation of protective ability of rust layers on weathering steels by potential measurement. Corros Eng 49:25-37

Leon Y, Saheb M, Drouet E, Neff D, Foy E, Leroy E, Dynes JJ, Dillmann P (2014) Interfacial layer on archaeological mild steel corroded in carbonated anoxic environments studied with coupled micro and nano probes. Corros Sci 88:23-35. doi:10.1016/j.corsci.2014.07.005

Leroy S, L'Héritier M, Delqué-Kolic E, Dumoulin J-P, Moreau C, Dillmann P (2015) Consolidation or initial design? Radiocarbon dating of ancient iron alloys sheds light on the reinforcements of French Gothic Cathedrals. J Archaeol Sci 53:190-201. doi:10.1016/j.jas. 2014.10.016

Leskelä M, Ritala M (2002) Atomic layer deposition (ALD): from precursors to thin film structures. Thin Solid Films 409:138-146. doi:10.1016/S0040-6090(02)00117-7

Marquardt AE, Breitung EM, Drayman-Weisser T, Gates G, Phaneuf RJ (2015) Protecting silver cultural heritage objects with atomic layer deposited corrosion barriers. Heritage Sci 3:1-12. doi:10.1186/s40494-015-0066-x 
Matero R, Ritala M, Leskelä M, Salo T, Aromaa J, Forsén O (1999) Atomic layer deposited thin films for corrosion protection. J Phys IV France 09:Pr8-493-Pr8-499. doi:10.1051/jp4: 1999862

Matthiesen H, Gregory D, Jensen P, Sørensen B (2004a) Environmental monitoring at Nydam, a waterlogged site with weapon sacrifices from the Danish Iron age. I: a comparison of methods used and results from undisturbed conditions. J Wetland Archaeol 4:55-74

Matthiesen H, Salomonsen E, Sørensen B (2004b) The use of radiography and GIS to assess the deterioration of archaeological iron objects from a water logged environment. J Archaeol Sci 31:1451-1461

Michelin A, Drouet E, Foy E, Dynes JJ, Neff D, Dillmann P (2013) Investigation at the nanometer scale on the corrosion mechanisms of the archaeological ferrous artifacts by STXM. J Anal At Spectrom 28:59-66

Monnier J, Dillmann P, Legrand L, Guillot I (2010a) Corrosion of iron from heritage buildings: proposal for degradation indexes based on rust layer composition and electrochemical reactivity. Corros Eng Sci Technol 45:375-380

Monnier J, Neff D, Réguer S, Dillmann P, Bellot-Gurlet L, Leroy E, Foy E, Legrand L, Guillot I (2010b) A corrosion study of the ferrous medieval reinforcement of the Amiens cathedral. Phase characterisation and localisation by various microprobes techniques. Corros Sci 52:695710

Monnier J, Guillot I, Legrand L, Dillmann P (2013) Reactivity studies of atmospheric corrosion of heritage iron artefacts. In: Dillmann P, Watkinson D, Angelini E, Adriens A (eds) Corrosion and conservation of cultural heritage metallic artefacts. Woodhead Publishing, Oxford, pp 285310

Muller J, Lorang G, Leroy E, Laik B, Guillot I (2010) Electrochemically synthesised bronze patina: characterisation and application to the cultural heritage. Corros Eng Sci Technol 45:322-326. doi:10.1179/147842210X12692706339265

Muller J, Laïk B, Guillot I (2013) $\propto$-CuSn bronzes in sulphate medium: influence of the tin content on corrosion processes. Corros Sci 77:46-51. doi:10.1016/j.corsci.2013.07.025

Neff D, Dillmann P, Bellot-Gurlet L, Beranger G (2005) Corrosion of iron archaeological artefacts in soil: characterisation of the corrosion system. Corros Sci 47:515-535. doi:10.1016/j.corsci. 2004.05.029

Paussa L, Guzman L, Marin E, Isomaki N, Fedrizzi L (2011) Protection of silver surfaces against tarnishing by means of alumina/titania-nanolayers. Surf Coat Technol 206:976-980. doi:10. 1016/j.surfcoat.2011.03.101

Pourbaix M (1977) Electrochemical corrosion and reduction. Corrosion and metal artifatcs : a dialogue between conservators and archaeologists 1-16

Puurunen RL (2005) Surface chemistry of atomic layer deposition: a case study for the trimethylaluminum/water process. J Appl Phys. doi:10.1063/1.1940727

Rangel CM, Fonseca IT, Leitão RA (1986) Some aspects of the electrochemical behaviour of mild steel in carbonate/bicarbonate solutions. Electrochim Acta 31:1659-1662. doi:10.1016/00134686(86)87089-X

Robbiola L, Blengino J-M, Fiaud C (1998) Morphology and mechanisms of formation of natural patinas on archaeological $\mathrm{Cu}-\mathrm{Sn}$ alloys. Corros Sci 40:2083-2111. doi:10.1016/S0010-938X (98)00096-1

Saheb M, Descostes M, Neff D, Matthiesen H, Michelin A, Dillmann P (2010a) Iron corrosion in an anoxic soil: comparison between thermodynamic modelling and ferrous archaeological artefacts characterised along with the local in situ geochemical conditions. Appl Geochem 25:1937-1948. doi:10.1016/j.apgeochem.2010.10.010

Saheb M, Neff D, Demory J, Foy E, Dillmann P (2010b) Characterisation of corrosion layers formed on ferrous artefacts buried in anoxic media. Corros Eng Sci Technol 45:381-387

Schlegel ML, Bataillon C, Benhamida K, Blanc C, Menut D, Lacour J-L (2008) Metal corrosion and argillite transformation at the water-saturated, high-temperature iron-clay interface: a microscopic-scale study. Appl Geochem 23:2619-2633 
Schlegel ML, Bataillon C, Brucker F, Blanc C, Prêt D, Foy E, Chorro M (2014) Corrosion of metal iron in contact with anoxic clay at $90{ }^{\circ} \mathrm{C}$ : characterization of the corrosion products after two years of interaction. Appl Geochem 51:1-14

Scott D, Eggert G (2009) Iron and steel in art: corrosion, colorants, conservation. Archetype Publications Ltd, Plymouth

Selwyn LS, Binnie NE, Poitras J, Laver ME, Downham DA (1996) Outdoor bronze statues: analysis of metal and surface samples. Stud Conserv 41:205-228. doi:10.1179/sic.1996.41.4.205

Shashoua Y, Matthiesen H (2010) Protection of iron and steel in large outdoor industrial heritage objects. Corros Eng Sci Technol 45:357-361. doi:10.1179/147842210X12710800383648

Spoto G, Ciliberto E, Allen GC, Younes CM, Piccardo P, Pinasco MR, Stagno E, Ienco MG, Maggi R (2000) Chemical and structural properties of ancient metallic artefacts: multitechnique approach to study of early bronzes. Br Corros J 35:43-47

Stratmann M (1987) The investigation of the corrosion properties of metals, covered with adsorbed electrolyte layers-a new experimental technique. Corros Sci 27:869-872

Stratmann M, Streckel H (1990) On the atmospheric corrosion of metals which are covered with thin electrolyte layers-II. Experimental results. Corros Sci 30:697-714

Stratmann M, Streckel H, Kim KT, Crockett S (1990) On the atmospheric corrosion of metals which are covered with thin electrolyte layers-III. The measurement of polarisation curves on metal surfaces which are covered by thin electrolyte layers. Corros Sci 30:715-734

Wang C, Lu B, Zuo J, Zhang S, Tan S, Suzuki M, Chase WT (1995) Structural and elemental analysis on the nanocrystalline $\mathrm{SnO}_{2}$ in the surface of ancient Chinese black mirrors. Nanostruct Mater 5:489-496. doi:10.1016/0965-9773(95)002 